\title{
Taste Evaluation of Potato Glycoalkaloids by the Aymara: A Case Study in Human Chemical Ecology
}

\author{
Timothy Johns ${ }^{1}$ and Susan L. Keen ${ }^{2}$
}

A chemical ecological model can be the basis for defining testable hypotheses concerning human interactions with plants. Selection by Aymara subsistence cultivators against toxic glycoalkaloids in the ongoing domestication of the Bolivian potato cultigen Solanum $\times$ ajanhuiri was used as a specific case study of human interactions with phytochemicals. In taste perception tests, Aymara subjects were able to discriminate between concentrations of pure glycoalkaloids in solution only above $20 \mathrm{mg} / 100 \mathrm{ml}$. Taste panel tests of potato clones indicated that glycoalkaloid levels are important to the Aymara in determining quality only as part of a decision-making process involving two character states: too high or acceptable. Glycoalkaloids in potatoes are regarded as toxic to humans above $20 \mathrm{mg} / 100 \mathrm{~g}$ fresh weight. Among the Aymara, a breakpoint in the curve for glycoalkaloid preference appears to occur between 20-38 mg/100 $\mathrm{g}$. This distinction is evident in the Aymara potato taxonomy which distinguishes bitter Auq'i ch'oke) from nonbitter (ch'oke) potatoes.

KEY WORDS: chemical ecology; glycoalkaloids; potatoes; taste perception.

\section{INTRODUCTION}

The original acquisition of empirical plant knowledge by humans must have been a dynamic process. An understanding of the active interaction of extant peoples with the plant world requires multidisciplinary approaches in human and plant biology. A chemical ecological perspective on her-

\footnotetext{
${ }^{1}$ Division of Biological Sciences and Museum of Anthropology, University of Michigan, Ann Arbor, Michigan 48109.

2Division of Biological Sciences, University of Michigan, Ann Arbor, Michigan 48109.
} 
bivore-plant interactions (Rosenthal and Janzen, 1979) can provide new insights into human plant use. The ways in which humans choose plants on the basis of chemical constituents provides a specific model of human-plant interactions with particular relevance for the understanding of the nutritional and medicinal uses of plants. The association of plants with particular chemical qualities combines taste and smell perception, physiological responses, and cognitive memory. The cultural record of plant use and behavior toward plants is communicated verbally and in the classification schemes contained in language.

Plant domestication offers an excellent focus for study of human chemical ecology because the direct interactions of humans with specific compounds has occurred over time, and its history is recorded in the genetic changes brought about in plants. Chemical selection in domesticated plants is a widespread phenomenon (Johns, 1985; Rindos, 1980).

Selection for reduction in the levels of potentially toxic glycoalkaloids characteristic of wild species of tuber-bearing species of potato, Solanum Section Petota, was clearly crucial to the development of the primitive diploid cultigen S. stenotomum Juz. et Buk. Relaxation of the restraint glycoalkoids imposed on the exploitation of potato tubers made this resource much more available to humans and probably facilitated population growth and cultural development of Andean peoples. Adaptation to frigid and arid conditions is important for potatoes grown on the altiplano of Peru and Bolivia. Genes for frost and drought resistance have been acquired through introgressive hybridization involving S. stenotomum and wild species, in particular $S$. acaule Bitt. and S. megistacrolobum Bitt. (Johns et al., 1987). The reintroduction of high levels of glycoalkaloids into potato cultigens through this hybridization, while a problem for Andean cultivators, provided an excellent model for studying the ongoing interaction of humans with plant chemicals as a determinant of the domestication process.

The Aymara Indians of the Bolivian altiplano depend on potatoes for a large part of their basic subsistence. Their potato nomenclature as tabulated by La Barre (1947) and Hawkes (1947) reflects considerable sophistication in recognizing and distinguishing varieties, and attention to subtle differences in potato characteristics and quality. De Lucca (1983) mentions that over 1000 names are used for directly describing potatoes by the Aymara. De Lucca (1983) and Hawkes (1947) list many more words that relate to potato cultivation and taxonomy, and to specialized ways of classifying potatoes.

Frost-resistance, yield, and palatability are important in the Aymara evaluation of potatoes (Huamán, 1975). Quechua-speaking farmers from Cuyo-cuyo, Peru, rate potato culinary quality primarily on the basis of flavor and dry matter content (Jackson, Hawkes, and Rowe, 1980), whereas Brush, Carney, and Huamán (1981) point to high dry matter as being the characteristic most sought by natives of central Peru. 
We hypothesize that Aymara cultivators have placed direct selection pressure on the chemical constituents of potato through their attention to taste quality. Selection is likely to be applied at the level of the human community acting over time on the potato gene pool. Both perceptual and cognitive processes would be involved in selection for particular tastes, and must be considered directly. Quantitative data on Aymara taste perception and preferences obtained in taste tests of pure compounds (Johns and Keen, 1985) demonstrated that salt, sour, and bitter substances are rated less pleasant in comparison to typical western populations. In the present study, the ability of an Aymara community to distinguish potatoes on the basis of taste was examined using standard sensory testing procedures as well as taste panel tests with several potato varieties.

The cultural mechanisms that mediate communication about potato tastes affect the evaluations of potato quality made by the community. We have described the Aymara taxonomy of taste (Johns and Keen, 1985). The Aymara have an expanded taste nomenclature for bitter substances and lack a clear concept of sourness. The unique taste taxonomy and taste preferences of the Aymara are explicable by dietary experience.

Brush (1980; Brush et al., 1981) has outlined the potato taxonomy of the Quechua of central Peru. The Aymara potato taxonomy has essentially the same structure (Table I). At the folk species level (Brush, 1980) taste quality is important for differentiating bitter and nonbitter potatoes, designated as $l u q^{\prime} i$ as ch'oke, respectively. Although attention to texture is important in folk variety groupings (La Barre, 1947), reference to taste per se, beyond the broad separation of bitter and nonbitter, is not evident in the potato nomenclature. However, for the Aymara, the importance of differences in potato taste is clear to any observer who has shared a typical Andean meal made up of a number of varieties of boiled potatoes.

Table I. Schematic Diagram of the Folk Taxonomy of Potatoes among the Aymara of the Bolivian Altiplano ${ }^{a}$

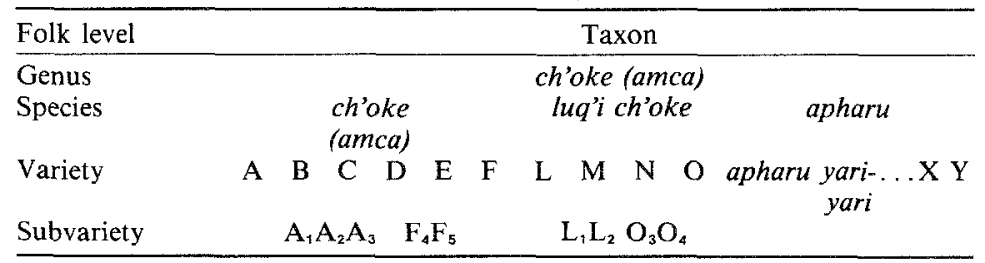

${ }^{a}$ The designations of folk levels follow the classification by Brush (1980) of potato names from central Peru. Folk species: ch'oke; cultivated potatoes that are edible after boiling. amca is an archaic word that retains some importance. luq $i$ : frostresistant potatoes which are recognized as bitter. apharu: wild potatoes; although it is recognized that some of these are edible, they are very seldom eaten. 


\section{GLYCOALKALOIDS AND POTATO TASTE QUALITY}

Although differences in taste quality are distinguishable to a casual taster or to an experimenter, it is not clear in a complex food item what principal or combination of principals is determinant. The characteristic flavor of potatoes results from a complex interaction of free amino acids, 5'nucleotides, simple sugars, phenolics, and glycoalkaloids (Solms and Wyler, 1979; Sinden, Deahl, and Aulenbach, 1976). Of interest in this study are the bitter and potentially toxic glycoalkaloids. Perception of these compounds has not been studied physiologically. Their perception appears to result, at least in part, from an astringent effect on oral membranes, perhaps in combination with direct effects on taste receptors. Solanine, the glycoalkaloid common in most potato cultigens, is considered toxic to humans above 20 $\mathrm{mg} / 100 \mathrm{~g}$ fresh weight $(0.02 \%$; Jadhav, Sharma, and Salunkhe, 1981). Cultivated potatoes generally have less solanine, and cases of poisoning are rare. Tubers of wild potato species vary in the identity and quantity of glycoalkaloids present (Schrieber, 1968; Osman et al., 1978; Gregory et al., 1981; Johns and Osman, 1986). Wild species in general have $100 \mathrm{mg} / 100$ $\mathrm{g}$ or more of total glycoalkaloids.

Human selection for reduced quantities of these alkaloids assumes an ability to recognize differences in alkaloid levels among potato varieties; to test this hypothesis, this study focuses on glycoalkaloid perception and preference while generally ignoring the possible role of other taste- and quality-contributing factors. The role of glycoalkaloids in determining human preference for whole potatoes was tested by analyzing potatoes used in the panel test for these constituents.

Taste tests were designed to address the capacity of humans to affect the domestication of the hybrid potato, Solanum X ajanhuiri Bitt. This important endemic cultigen of the western Bolivia altiplano coexists in an evolutionary complex with wild, weed, and cultivated potato taxa (Johns and Keen, 1986; Johns et al., 1987). Interactions of humans with $S$. X ajanhuiri provided a model system of chemical selection that has been considered from both biosystematic (Johns et al., 1987; Johns and Osman, 1986) and ethnobotanical (Johns and Keen, 1986) points of view. In this study, clones of ajawiri and yari varieties of $S$. X ajanhuiri, and five samples from weed $S$. X ajanhuiri populations, similar in tuber appearance to the primitive yari varieties, were included in a panel test along with tubers of other cultigens.

Preliminary analyses of clones of $S$. megistacrolobum, the wild relative of $S$. X ajanhuiri, obtained from the Potato Introduction Station in Sturgeon Bay, Wisconsin, indicated that tomatine was the major alkaloid in $S$. megistacrolobum (Johns and Osman, 1986). Since ajawiri clones of $S$. $\times$ ajanhuiri, at least, were known to contain $\alpha$-solanine and $\alpha$-chaconine (Osman et al., 1978), the alkaloids characteristic of most cultivated potatoes, we 
hypothesized that preference and selection for solanidine-containing glycoalkaloids ( $\alpha$-solanine and $\alpha$-chaconine) vs. those containing tomatidine, e.g., tomatine, could be a driving force in potato domestication (Johns, 1986a). Evidence from animal studies indicated that, in general, tomatine is not more toxic than $\alpha$-solanine and $\alpha$-chaconine (Nishie, Norred, and Swain, 1975). However, from a series of potato glycoalkaloids including $\alpha$ solanine and $\alpha$-chaconine, tomatine showed the greatest potency in producing cardiotonic effects on isolated frog ventricle (Nishie, Fitzpatrick, Swain, and Keyl, 1976). The ability of humans to discern quantitative and qualitative differences in glycoalkaloids and to distinguish solanidine- and tomatidine-based glycoalkaloids was examined using suprathreshold tests of six-fold concentrations of tomatine and of a mixture of $\alpha$-solanine and $\alpha$-chaconine.

\section{METHODS}

\section{Taste Panel Tests of Potato Quality}

A panel of 14 residents of Caquiaviri, Province of Pacajes, Department of La Paz, Bolivia (altitude $3950 \mathrm{~m}$ above sea level) was enlisted to evaluate 14 varieties of potatoes. Potato varieties were selected to represent a probable wide variation in glycoalkaloid content. Potatoes were obtained both locally and outside the Caquiaviri area. Included with three clones of $S$. X ajanhuiri cultigens and five clones of weed $S$. X ajanhuiri were tubers of S. stenotomum, S. tuberosum L., S. X juzepczukii Buk. and S. acaule $\mathrm{X}$ ajanhuiri (Johns et al., 1987). The varieties and their sources are recorded in Table II.

Potato varieties were prepared separately. The local method of boiling the tubers in a minimal volume of water without salt was followed. Potatoes were prepared the night before the test and were served at room temperature consistent with the local custom. Tubers were peeled fresh before each new subject entered the room to minimize visual recognition. Individuals were presented with single tubers in the case of small tubers, and portions equivalent in size to the small tubers when the tubers were large.

Subjects were tested individually. In order to minimize preconceived expectations and influences from other panelists, subjects were not allowed to witness the procedure before their turn. Each subject tasted ten randomly presented potato tubers. All 14 subjects tasted samples 1-6. Only limited quantities of four of the clones of weed $S$. X ajanhuiri were available and each subject tested only two of these (numbers 11, 12, 13, and 14). Each subject tested one sample of yari (7 or 8 ) and one of sisu (9 or 10). Samples 7-14 were arbitrarily distributed such that each variety was tested seven times 


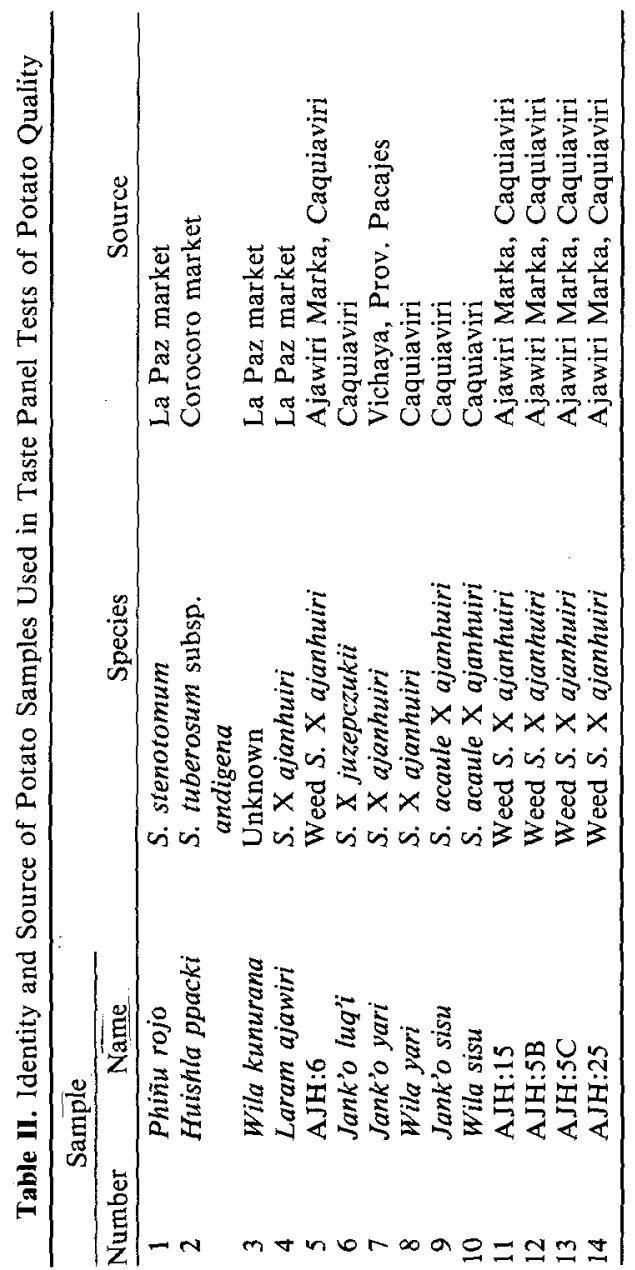


and that each person tested a unique subset of the varieties. Samples were presented in uniform plastic dishes labeled with a symbol code. Subjects tasted each tuber and after chewing were instructed to either swallow or spit. They rinsed their mouths with drinking water between samples.

The subjects responded to the stimuli in two manners. Both a scoring method and a ranking method (Larmond, 1977) were used with each subject. First, individuals were asked to score the specimens for bitterness or sweetness on the following 5 -point scale: $5=$ very bitter, $4=$ slightly bitter, 3 = without flavor, neither bitter nor sweet, 2 = flavorful, sweet, and 1

$=$ very flavorful, very sweet. Bitterness and sweetness are used as contrasting concepts of good and bad in the Aymara taste taxonomy (Johns and Keen, 1985) and are used in this sense here. Sweet means good in this context, not the taste of sugar. This experiment is confounded by the apparently contextual nature of the Aymara terms for bitter and sweet, and ratings should be considered from this perspective. The scale described above is similar to one used in a panel test by Huamán (1975) in which workers from Huancayo, Peru were asked to evaluate potato bitterness.

After they had scored each potato sample, the Aymara subjects were also asked to rank samples in order of preference. Taste scorings and preference rankings were compared by estimation of $95 \%$ confidence intervals on mean values. The $95 \%$ confidence intervals were calculated using the Bonferroni adjustment for simultaneous estimation at $\alpha=0.5$ (Neter and Wasserman, 1974).

The panel comprised eight women and six men. The subjects were between 18-67 years of age with a median age of 34. All subjects were tested for PTC sensitivity using PTC paper strips obtained from Ward's Natural Science Establishment, Inc., Rochester, N.Y., and were uniformly tasters. The panel test took place in a single unheated room in a private residence between 11:45 AM and 4:45 PM on June 11, 1983. Uncooked samples of all 14 tuber specimens were preserved in $95 \%$ ethanol and saved for subsequent qualitative and quantitative analyses of glycoalkaloids using the methods outlined in Johns and Osman (1986).

\section{Taste Perception of Tomatine and Solanine-Chaconine}

In the taste perception tests reported previously (Johns and Keen, 1985), subjects rated compounds representing sweet, salty, sour, and bitter for both taste intensity and taste pleasantness. The "sip-and spit" method of stimulation and a magnitude estimation method for recording sensations were used. Sixteen of the subjects included in the taste perception procedure were also presented with two sets of triplicate samples made up of six successive 
half dilutions each of tomatine and a $\alpha$-solamine- $\alpha$-chaconine mixture. The highest concentration of both solanine-chaconine and tomatine was 0.00092 M. This corresponds to $80 \mathrm{mg} / 100 \mathrm{ml}$ of solanine, the standard compound to which glycoalkaloid levels in potatoes were routinely compared. Throughout the text of this paper, concentrations will be expressed in $\mathrm{mg} / 100$ $\mathrm{ml}$ to facilitate comparison with studies examining potato glycoalkaloid content. Samples were dissolved in $0.001 \mathrm{M} \mathrm{HCl}$ and were subsequently diluted in the $\mathrm{HCl}$ mixture. Samples were presented randomly as in the general study (Johns and Keen, 1985), and subjects ranked the solutions for both preference and intensity.

Eight tests were carried out between January 24-29, 1983, and eight between May 30 and June 8, 1983. The subjects, eight men and eight women, were all from the Caquiaviri area. Ages ranged between 19-54 with a median age of 37 years.

Tomatine was purchased from Sigma Chemical Co., St. Louis, Missouri. The solanine-chaconine mixture was extracted and purified from incubated slices of potato tubers (Johns, 1985). Solanine and chaconine were both triose glycosides of the same aglycone, solanidine. Because their molecular weight differs by only $1.8 \%$, a weighted sample effectively provided a known molar concentration of solanidine glycosides.

The perceptions of intensity and preference for increasing concentrations of solanine-chaconine and tomatine were tested for significant differences using analysis of variance (ANOVA) and Student's $t$-test.

\section{RESULTS}

\section{Taste Panel of Potato Quality}

The mean values of the ranking (in order of preference) and scoring (for bitterness or sweetness) test methods are recorded in Table III. Phiñu rojo stood out as the specimen scored as least bitter (and therefore with the best flavor), and the one ranked as the most preferred. The wide $95 \%$ confidence intervals produced few significant differences between.samples, although the score and ranking methods show similar patterns. Phiñu rojo was scored as significantly different from jank'o luq'i (6), wila sisu (10), huishla ppacki (2), and two of the weed $S$. X ajanhuiri samples $(5,3)$ in both analyses. In Table III, dashed lines separate phiñu rojo and these specimens that show significant differences from phiñu rojo on the basis of preference from the remaining intermediate specimens which are not significantly different from either of these two groups. The specimens, with the exception of $\mathrm{AJH}: 25$, fall into the same groups when the scoring method is used. 


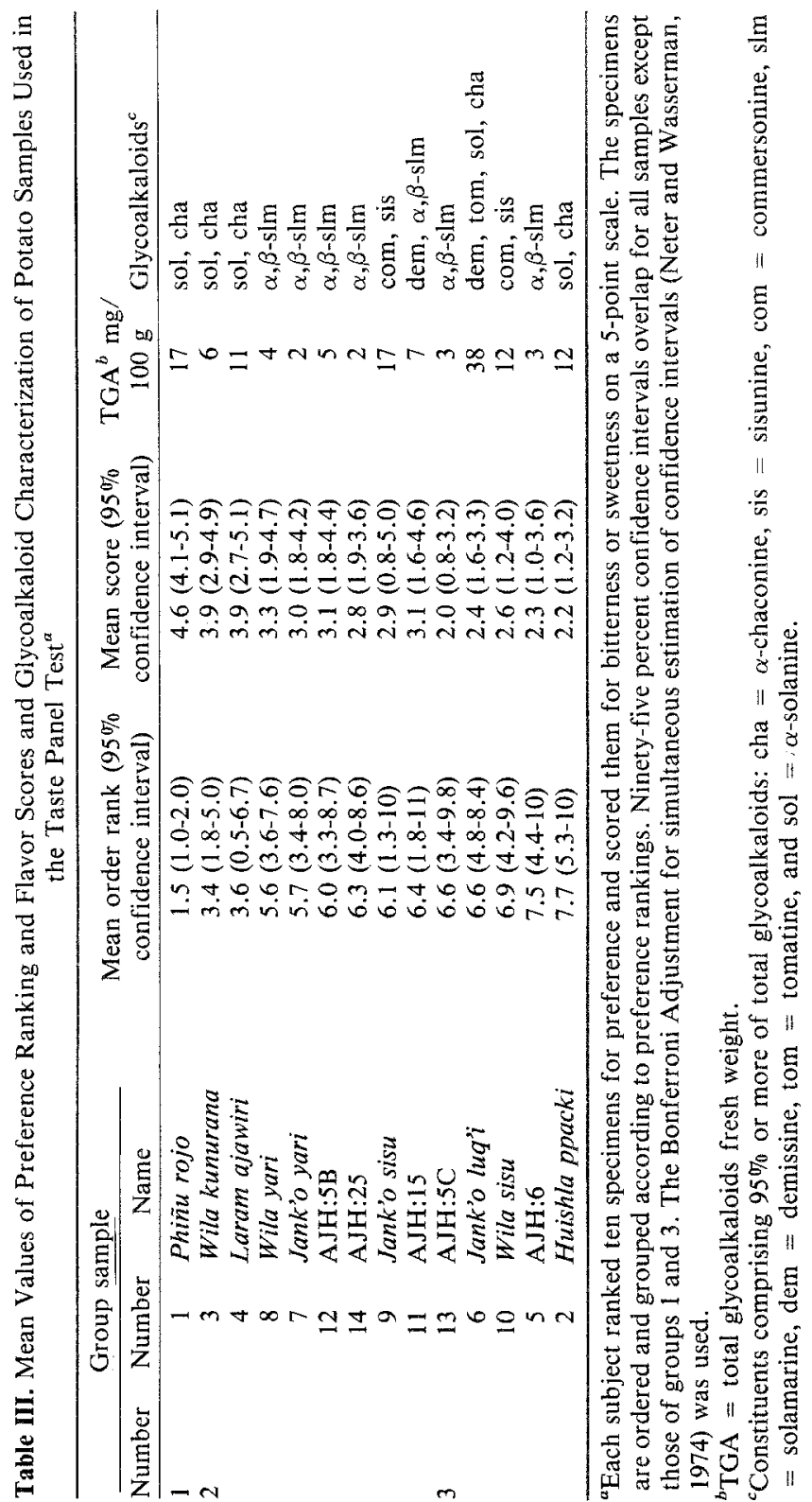


The glycoalkaloid constituents and total glycoalkaloids of the tuber specimens used in this test are recorded in Table III. The glycoalkaloids detected in individual clones are consistent with the results recorded for these taxa previously (Johns and Osman, 1986; Osman, Johns, and Price, 1986). Samples numbered $1,2,3$, and 4 contained $\alpha$-solanine and $\alpha$-chaconine as major constituents. Other samples were characterized by mixtures of demissidine, tomatidine, tomatidenol, and solanidine-containing glycoalkaloids. The manner in which the panel subjects rated potatoes for flavor or preference is not correlated with total glycoalkaloids or with the pattern of individual glycoalkaloids. The specimen with the greatest amount of glycoalkaloid, jank'o luq'i was one of the most bitter and least preferred. However, specimens that were even less preferred had glycoalkaloid constituents and total glycoalkaloid levels less than or comparable to specimens that ranked much higher. Although phiñu rojo (1) and huishla ppacki (2) ranked second and third in total glycoalkaloid content and both were characterized by $\alpha$ solanine and $\alpha$-chaconine, they are the most and least preferred specimens, respectively. Jank'o luq $i$ with $38 \mathrm{mg} / 100 \mathrm{~g}$ was the only sample in the study containing more than $20 \mathrm{mg} / 100 \mathrm{~g}$ total glycoalkaloids.

\section{Taste Perception of Tomatine and Solanine-Chaconine}

The subject population responded to the test for tomatine and solaninechaconine perception with relatively little sensitivity to these glycoalkaloids over most of the concentrations presented (Fig. 1). An analysis of variance showed no significant difference in strength rating between concentrations of glycoalkaloids of $40 \mathrm{mg} / 100 \mathrm{ml}$ or less (solanine-chaconine: $P=0.19$; tomatine: $P=0.89$ ). Subjects did perceive $80 \mathrm{mg} / 100 \mathrm{ml}$ solutions as significantly stronger than $40 \mathrm{mg} / 100 \mathrm{ml}$ ( $t$-test for solanine-chaconine: $P$ $=0.004$; tomatine: $P=0.01$ ). Equivalent molar solutions of tomatine and the solanine-chaconine mixture were perceived as equivalent for all concentrations.

As the concentration of solanine-chaconine increased above $20 \mathrm{mg} / 100$ $\mathrm{ml}$, subjects showed a decreasing preference for solanine-chaconine with significant differences in preference over the range $80-20 \mathrm{mg} / 100 \mathrm{ml}$ (ANOVA $P=0.0006$ ). Between $20 \mathrm{mg} / 100 \mathrm{ml}$ and $2.5 \mathrm{mg} / 100 \mathrm{ml}$, subjects were unable to detect significant differences $(P=0.63)$. The group of subjects was not able to detect any significant differences in the concentration of tomatine over the full range of the test $(80-40 \mathrm{mg} / 100 \mathrm{ml}: P=0.19(t-$ test); $40-2.5 \mathrm{mg} / 100 \mathrm{ml}: P=0.99$ (ANOVA)). The subject group showed no differences in response to tomatine vs. solanine-chaconine at concentrations below $20 \mathrm{mg} / 100 \mathrm{ml}$. However, solanine-chaconine was rated less 


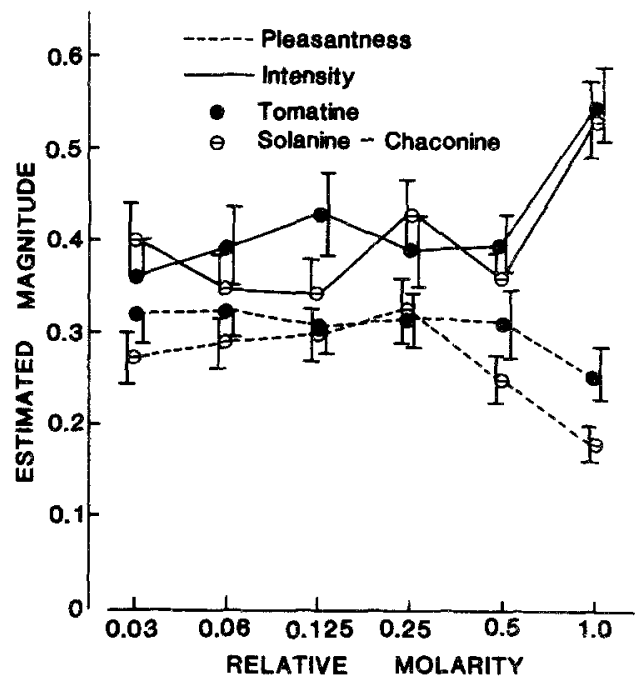

Fig. 1. Relationship of perceived intensity and pleasantness to concentration for the glycoalkaloids tomatine and a solanine-chaconine mixture. Concentrations are relative to the greatest concentration which is $0.00092 \mathrm{M}(80 \mathrm{mg} / 100 \mathrm{ml}$ solanine) and are given in logarithmic units. Subjects recorded their responses following a method of line matching (Johns and Keen, 1985). Each subject's responses were converted to ratios (estimated magnitudes) by comparison with the greatest responses for pleasantness and intensity for all of the test solutions, i.e., including glucose, sodium chloride, citric acid, quinine sulfate (Johns and Keen, 1985), and glycoalkaloids, presented.

favorably than tomatine at both $40 \mathrm{mg} / 100 \mathrm{ml}$ and $80 \mathrm{mg} / 100 \mathrm{ml}$, although the difference was significant at $80 \mathrm{mg} / 100 \mathrm{ml}(t$-test, $P=0.04)$, but not significant at $40 \mathrm{mg} / 100 \mathrm{ml}(P=0.16)$.

\section{DISCUSSION}

\section{Glycoalkaloid Content and Potato Taste Quality}

On the basis of a taste perception study, their folk taxonomy of taste, and a dietary survey, we suggested previously (Johns and Keen, 1985) that the Aymara are attuned to bitter and unpleasant plant-derived substances in their diet. The limited resources of the high-altitude environment dictate 
dependence on potentially toxic plant foodstuffs, the most important of which is the potato. The panel tests of potato taste quality reported here provide quantitative support for observations that the Aymara and other Andeans are capable of making judgments of potato quality on the basis of taste. However, the groupings into which the test population placed samples of wild and cultivated potato tubers do not appear to be based, at least primarily, on glycoalkaloid content. Within the range of glycoalkaloids present in potatos used in the panel test, with the exception of jank'o luq' $i$ (that is less than $20 \mathrm{mg} / 100 \mathrm{ml}$ ), some other factor, or combination of taste and flavor factors, determines potato quality.

As mentioned above, flavor in potatoes is determined by a complex combination of constituents, including glycoalkaloids. Factors such as dry matter and texture probably played some role in the judgments made by the Aymara in this study. Subjects tended to confound bitterness and unpleasantness in the scoring part of the panel test, and it is likely that their judgments of flavor quality involve a combination of factors of which the bitter taste is only one.

Sinden et al. (1976) reported that, in tests with a trained taste panel of North American subjects, potatoes with total glycoalkaloid levels above $14 \mathrm{mg} / 100 \mathrm{~g}$ were consistently rated as bitter. The Aymara population actually most preferred a potato variety with as much as $17 \mathrm{mg} / 100 \mathrm{~g}$ total glycoalkaloids. The present experiment is not directly comparable to that carried out by Sinden et al. (1976), but these two results are not greatly different. The difference suggests that the Aymara have a slightly higher threshold level of response to glycoalkaloid content. The most bitter potato, jank'o luq'i, contained $38 \mathrm{mg} / 100 \mathrm{~g}$ total glycoalkaloids. Although the Aymara potato taxonomy (Table I) makes only one distinction on the basis of taste, this is an important determinant in relation to Aymara perception of and behavior toward potatoes. Potatoes are either luq'i or ch'oke, bitter or nonbitter. Jank'o luq'i is typical of the former category and are usually processed for consumption (Johns, 1986b; Werge, 1979); all of the other cultivated potatoes used in this study are placed in the latter. The participants' decisions to reject the former sample were likely based on its high level of glycoalkaloids. Thus, a threshold of glycoalkaloid unacceptability for the Aymara appears to be between $17-38 \mathrm{mg} / 100 \mathrm{~g}$.

If the Aymara reject glycoalkaloids at a higher level than other populations, their inferred acuity to bitter and toxic substances (Johns and Keen, 1985) might appear to be unsupported. However, recognition of glycoalkaloid contents at a moderately high level (such as $17 \mathrm{mg} / 100 \mathrm{~g}$ ) may, in fact, be one key to a positive evaluation of potato quality by the Aymara. An ability to make decisions of acceptability at moderately high levels of glycoalkaloids does not mean that the Aymara are insensitive to these compounds. Bitter 
potatoes such as jank'o $l u q^{\prime} i$ are eaten unprocessed immediately after harvest time (Johns and Keen, 1985). Perhaps in a resource-limited environment, the Aymara have developed a higher level of acceptance for glycoalkaloids. More data collected from taste panel tests using potatoes containing between $14-38 \mathrm{mg} / 100 \mathrm{~g}$ glycoalkaloids would test this hypothesis of the Aymara acceptance for glycoalkaloids.

The differentiation of potato quality at levels somewhere between 17-38 $\mathrm{mg} / 100 \mathrm{~g}$ is consistent with data from the study on the perception of solaninechaconine. Subjects determined no differences in strength at concentrations below $20 \mathrm{mg} / 100 \mathrm{ml}$. However, as they perceived an increase in concentration up to $80 \mathrm{mg} / 100 \mathrm{ml}$, they also showed a significant and increasing rejection of this mixture of compounds. Although concentrations expressed as $\mathrm{mg} / 100 \mathrm{ml}$ in aqueous solution or as $\mathrm{mg} / 100 \mathrm{~g}$ in the fresh weight of potato tissue are not strictly equitable, and are unlikely to be perceived as equivalent, the results of studies done with pure compounds support the conclusions from the panel tests using potato tubers that a break-point for solanine-chaconine preference by the Aymara occurs roughly between $20-38 \mathrm{mg} / 100 \mathrm{~g}$.

The hypothesis that the Aymara would reject potatoes on the basis of tomatine vs. solanine-chaconine content was clearly unsupported. Based on this hypothesis, we predicted that solanine-chaconine would be preferred over tomatine. In contrast, while tomatine and solanine-chaconine are perceived as equivalent in intensity, solanine-chaconine received significantly lower preference ratings than tomatine. The relative rejection of solanine-chaconine by the Aymara could represent an experimental sensitivity to the solanidine glycoalkaloids encountered in their diet. Rejection of solanine and chaconine may represent a conditioned response to exposure to high levels of these compounds, or even genetic selection for increased sensitivity to these compounds which form an intrinsic part of their diet. However, differences in physiological perception of compounds does not necessarily have adaptive significance. While the differential acceptability of tomatine vs. solaninechaconine may have a physiological basis, it could also be a chance effect. The hypothesis that this effect seen in the Aymara population represents a conditioned or genetic difference could be tested under controlled conditions with Aymara and non-Aymara populations living under different dietary conditions.

\section{Chemical Selection of Potato Varieties}

It is apparent from these data that glycoalkaloid concentration plays only a minimal role in the ongoing selection and domestication of potato varieties. Potatoes will be evaluated for glycoalkaloids alone in terms of two 
character states, too high or acceptable, and not likely as part of a more subtle selection process that was envisioned at the onset of this study. Any role that glycoalkaloids may play in combination with other compounds or factors as a determinant of flavor quality is difficult to entangle.

Three of the five clones of weed $S$. X ajanhuiri included in the taste panel test are equally or more acceptable on the basis of taste than many of the clones currently grown by the Aymara. It would appear, then, that the weed population of $S$. X ajanhuiri contains clones that, if all other factors were equivalent, should readily be accepted into the cultivated gene pool. In view of the size achieved by some weed $S$. X ajanhuiri tubers used in this study, these hybrids between wild and cultivated potatoes would seem likely candidates for domestication. Sample 11, for example, produced tubers up to $11 \mathrm{~cm}$ in length in the field, and was as acceptable from a culinary standpoint as yari and sisu, two cultivated potatoes with many primitive characteristics.

\section{Human Chemical Ecology}

The interactions of humans with their phytochemical environment can best be understood by looking at evolutionary factors and processes that determine our biological and cultural responses to chemicals. Certainly physiological perception reflects basic nutritional and survival concerns. Behavioral response for avoiding toxic compounds, such as conditioned aversions (Rozin, 1976) and geophagy (Johns, 1986b), reflect evolutionary history. Analogies to the food procurement patterns of humans can be found in the behavior of modern primates. Medicinal plant use in humans has striking parallels to certain behaviors of plant utilization recently observed in chimpanzees (Wrangham and Nishida, 1983). Herbal medicine may be the culmination of a long evolutionary process rather than a unique human behavior.

The evolutionary process that determines human response to plant chemicals is difficult to approach directly. Ultimately, investigations in this field will center on comparisons among populations, whether they be populations of primate foragers, human hunter-gatherers or human agriculturalists. This investigation focused on the Aymara of the Province of Pacajes, Bolivia. It considered the interactions of a single group of subsistence agriculturalists with one group of chemicals, glycoalkaloids, from one type of plant, the potato. This highly simplified vision of human-plant interactions provided a testable model with which to exploit an expanding base of scientific data in plant and human biology. Case studies in human chemical ecology have the potential to increase our understanding of this important part of the evolutionary process. 


\section{ACKNOWLEDGMENTS}

This research was supported by a Natural Sciences and Engineering Research Council Canada Postgraduate Scholarship and a Natural Science Foundation Dissertation Grant (DEB82-08298) to T. Johns. The International Potato Center (CIP), Lima, CIDA, and the Colegio Tecnico Agropecuario Kalla Centro (SENET, Bolivia) provided logistical support. We are grateful for the assistance of Carlos Santalisas, George M. Hatfield, Leander J. Valdes, Stanley F. Osman, Michael M. Martin, Susan V. Poats, Nelly Fong, Stephen B. Brush, and Richard I. Ford.

\section{REFERENCES}

Brush, S. (1980). Potato taxonomies in Andean agriculture. In Brokencha, D. W., Warren, D. M., and Werner, O. (eds.), Indigenous Knowledge Systems and Development. University Press of America, Lanham, pp. 37-47.

Brush, S. B., Carney, H. J., and Huamán, Z. (1981). Dynamics of Andean potato agriculture. Economic Botany 35: 70-88.

De Lucca, M. (1983). Diccionario Aymara-Castellano Castellano-Aymara. Comision de Alfabetizacion y Literatura en Aymara, La Paz.

Gregory, P., Sinden, S. L., Osman, S. F., Tingey, W. M., and Chessin, D. A. (1981). Glycoalkaloids of wild, tuber-bearing Solanum species. Journal of Agricultural and Food Chemistry 29: 1212-1215.

Hawkes, J. G. (1947). On the origin and meaning of South American Indian potato names. Journal of Linnean Society, Botany 53: 205-250.

Huamán, Z. (1975). The Origin and Nature of Solanum ajanhuiri Juz et Buk., a South American Cultivated Diploid Potato. Ph.D. dissertation, University of Birmingham, U.K.

Jackson, M. T., Hawkes, J. G., and Rowe, P. R. (1980). An ethnobotanical field study of primitive potato varieties in Peru. Euphytica 29: 107-113.

Jadhav, S. J., Sharma, R. P., and Salunkhe, D. K. (1981). Naturally occurring toxic alkaloids in foods. CRC Critical Reviews in Toxicology 9: 21-104.

Johns, T. A. (1985). Chemical Ecology of the Aymara of Western Bolivia: Selection for Glycoalkaloids in the Solanum $X$ ajanhuiri Domestication Complex. Ph.D. dissertation, University of Michigan, Ann Arbor.

Johns, T. (1986a). Chemical selection in Andean domesticated tubers as a model for the acquisition of empirical plant knowledge. In Etkin, N. L. (ed.), Plants Used in Indigenous Medicine and Diet: Biobehavioral Approaches. Redgrave Publishers, South Salem, New York, pp. 266-288.

Johns, T. (1986b). The detoxification function of geophagy and the domestication of the potato. Journal of Chemical Ecology 12: 635-646.

Johns, T., and Keen, S. L. (1985). Determinants of taste perception and classification among the Aymara of Bolivia. Ecology of Food and Nutrition 16: 253-271.

Johns, T., and Keen, S. L. (1986). Ongoing evolution of the potato in the altiplano of western Bolivia. Economic Botany 40: 409-424.

Johns, T., and Osman, S. F. (1986). Glycoalkaloids of Solanum Series Megistacrolobum and related potato cultigens. Biochemical Systematics and Ecology 14: 651-655.

Johns, T., Huamán, Z., Ochoa, C. M., and Schmiediche, P. E. (1987). Relationships among wild, weed and cultivated potatoes in the Solanum X ajanhuiri complex. Systematic Botany. In press.

La Barre, W. (1947). Potato taxonomy among the Aymara Indians of Bolivia. Acta Americana 5: $83-103$. 
Larmond, E. (1977). Laboratory Methods for Sensory Evaluation of Food. Canada Department of Agriculture Publication 1637, Ottawa.

Neter, J., and Wasserman, W. (1974). Applied Linear Statistical Models. R. D. Irwin, Illinois.

Nishie, K., Norred, W. P., and Swain, A. P. (1975). Pharmacology and toxicology of chaconine and tomatine. Research Communications in Chemical Pathology and Pharmacology 12: 657-667.

Nishie, K., Fitzpatrick, T. J., Swain, A. P., and Keyl, A. C. (1976). Positive inotropic action of Solanaceae glycoalkaloids. Research Communications in Chemical Pathology and Pharmacology 15: 601:607.

Osman, S. F., Herb, S. F., Fitzpatrick, T. J., and Schmiediche, P. (1978). Glycoalkaloid composition of wild and cultivated tuber-bearing Solanum species of potential value in potato breeding programs. Journal of Agricultural and Food Chemistry 26: 1246-1248.

Osman, S. F., Johns, T. A., and Price, K. R. (1986). Sisunine, a glycoalkaloid found in hybrids between Solanum acaule and Solanum.X ajanhuiri. Phytochemistry 25: 967-968.

Rindos, D. (1980). Symbiosis, instability and the origins and spread of agriculture: A new model. Current Anthropology 21: 751-772.

Rosenthal, G. A., and Janzen, D. H. (1979). Herbivores: Their Interaction with Secondary Plant Metabolites. Academic Press, New York.

Rozin, P. (1976). The selection of food by rats, humans and other animals. Advances in the Study of Behavior 6: 21-76.

Schrieber, K. (1968). Steroidal alkaloids: The Solanum group. Alkaloids 10: 1-192.

Sinden, S. L., Deahl, K. L., and Aulenbach, B. B. (1976). Effects of glycoalkaloids and phenolics on potato flavor. Journal of Food Science 41: 520-523.

Solms, J., and Wyler, R. (1979). Taste components of potatoes. In Boudreau, J. (ed.), ACS Symposium Series No. 115.

Werge, R. W. (1979). Potato processing in the central highlands of Peru. Ecology of Food and Nutrition 7: 229-234.

Wrangham, R. W., and Nishida, T. (1983). Aspilia spp. leaves: A puzzle in the feeding behavior of wild chimpanzees. Primates 24: 276-282. 